\title{
PROPOSTAS DE CRITÉRIOS LOCACIONAIS PARA IMPLEMENTAÇÃO DE BASES DE APOIO LOGÍSTICO OFFSHORE À SERVIÇO DA INDÚSTRIA DO PETRÓLEO
}

\author{
Gustavo Nunes \\ COPPE/UFRJ \\ gustavo.nunes@labfuzzy.coppe.ufrj.br \\ Carlos Alberto Nunes Cosenza \\ COPPE/UFRJ \\ cosenzacoppe@gmail.com \\ Antonio Morim \\ COPPE/UFRJ \\ antonio.morim54@gmail.com \\ Fabio Krykhtine \\ COPPE/UFRJ \\ krykhtine@labfuzzy.coppe.ufrj.br \\ Luiz Eduardo Sá Fortes \\ COPPE/UFRJ \\ safortes@labfuzzy.coppe.ufrj.br
}

\begin{abstract}
Resumo
O modelo no qual o homem desenvolveu seus processos produtivos baseou-se na extração e utilização de matrizes energéticas naturais e não renováveis, como a lenha, o carvão e o petróleo, sendo rígido no curto e médio prazo quanto à estas fontes, fazendo com que a busca e o uso dos combustíveis fósseis seja não só legítima, mas necessária à atividade econômica, principalmente se o energético em questão for o petróleo. Sendo a dotação brasileira localizada majoritariamente em alto mar, reforçada pelas novas descobertas no présal, eleva-se a demanda por elos entre os modais terrestres e marítimos na forma de portos e bases de apoio para as operações logísticas offshore. Pela importância e penetração do petróleo tanto como produto como indústria, preconiza-se que ações e políticas que facilitem os empreendimentos dessas bases são de interesse estratégico nacional. Este trabalho visa contribuir neste propósito. Com base na metodologia COPPE-COSENZA de hierarquização e localização industrial foram identificados e parametrizados critérios de apoio à decisão locacional para implantação de bases de apoio logístico offshore, cujas iniciativas podem contribuir ao desenvolvimento brasileiro de duas formas seminais: mitigando possíveis gargalos no setor e explorando potencialidades locais para geração de renda e desenvolvimento econômico e social.

Palavras-chaves: Logística e Transportes; Localização Industrial; Petróleo; COPPECosenza.

Abstract

The model in which the man has developed its production processes was based on the extraction and use of natural and non-renewable energy sources, such as wood, coal and oil, being rigid in the short and medium term, making the search and the use of fossil fuels is not only legitimate, but necessary for economic activity, especially if the source in question is oil. Being the Brazilian endowment located mostly offshore, enhanced by new discoveries in the pre-salt layer, raises the demand for linkages between land and sea modals, in the form of ports and offshore logistics supply bases. By importance and penetration of oil as a product and industry as well, it is recommended that actions and policies that facilitate the enterprises
\end{abstract}


of these bases are subject of national strategic interest. This work aims to contribute in this regard. Based on the methodology COPPE-COSENZA of tiering and industrial location, were identified and parameterized locational decision support criteria for deployment of offshore logistics supply bases, whose initiatives can contribute to the development of two seminal forms: mitigating possible bottlenecks in the sector and exploring potential locations for income generation and economic and social development.

Keywords: Logistics and Transport; Industrial Location; Petroleum; COPPE-Cosenza

\section{INTRODUÇÃO}

Existe uma diretriz em voga na discussão social, não apenas brasileira, mas mundial: crescimento e desenvolvimento com sustentabilidade, ou seja, a capacidade de suprir nossas necessidades sem comprometer a capacidade de suprimento de gerações futuras. Grande parte desta "insustentabilidade" reside no como o ser humano gera a energia necessária para executar seus processos, tanto os domésticos quanto os produtivos. $\mathrm{O}$ modelo no qual tais processos evoluíram baseou-se na extração das matrizes energéticas diretamente na natureza, como a lenha, o carvão e o petróleo.

Porém, o modelo de desenvolvimento e crescimento econômico atual, baseado em energia oriunda de recursos não renováveis possui certas complexidades e idiossincrasias que o tornam relativamente rígido no curto e médio prazo, fazendo com que a busca e o uso dos combustíveis fósseis seja, não só legítima, mas necessária à manutenção do modo de vida humano e à geração da renda necessária à sua subsistência.

Dado este modelo de desenvolvimento, deter esses recursos em território nacional é como portar um bilhete premiado, "distribuído" aleatoriamente em tempo remoto pela natureza. E o prêmio é especialmente maior se sua dotação for de petróleo; como fim, como garantia do fornecimento da energia necessária a produção e ao desenvolvimento, bem como por seu valor intrínseco, refletido em seu valor de mercado; e como meio, pela complexidade e amplo penetração de sua cadeia produtiva, produzindo reflexos e externalidades positivas capazes de alavancar todo um sistema econômico, constituido-se, portanto, tanto um objetivo como uma oportunidade.

E esta riqueza se encontra majoritariamente em alto mar, reforçada pelas novas descobertas na camada pré-sal, demandando uma estrutura em terra que possibilite o provimento de todas as necessidades das instalações produtoras offshore, capaz de embarcar e receber materiais de todo tipo, atividade desempenhada por portos ou por bases de apoio logístico offshore. Tais bases são o elo entre os modais terrestres e marítimos, como o coração do sistema, bombeando e recebendo o fluxo de materiais e pessoas que fazem tudo acontecer. Fácil ver a criticidade do setor para o bom andamento deste sistema produtivo e para o bom proveito em termos econômicos e sociais deste "bilhete premiado natural" e a otimização do desenvolvimento desta indústria.

Logo, preconizamos que ações e políticas que facilitem os empreendimentos e estabelecimentos dessas bases são de interesse nacional e devem ser pauta no debate social. Neste trabalho busca-se contribuir neste propósito.

O sucesso de qualquer empreendimento industrial depende de um estudo locacional adequado, onde são definidas as características desejadas em uma área e seus graus de relevância para o projeto. Com base na metodologia do modelo COPPE-COSENZA de hierarquização e localização industrial, foram levantados, definidos e parametrizados critérios de apoio à decisão locacional para implantação de bases de apoio logístico offshore, cujas iniciativas podem contribuir ao desenvolvimento brasileiro de duas formas seminais: primeiro, mitigando possíveis gargalos no setor de apoio logístico offshore a serviço da indústria do petróleo, tão cruciais e reflexivos na economia do país; e segundo, desenvolvendo polos atratores de capitais produtivos, explorando potencialidades locais para geração de renda e desenvolvimento econômico e social. 


\section{CRITÉRIOS LOCACIONAIS}

Seguindo as diretrizes iniciais da metodologia do modelo de localização industrial COPPE-COSENZA para seleção de localidades para implementação de bases de apoio logístico offshore foram propostas neste trabalho 22 características a serem observadas nas áreas pré-selecionadas, agrupadas em quatro macro categorias (engenharia, meio ambiente, produção e transporte) e classificadas em quatro grupos de acordo com seu nível de relevância ao projeto: [A] Não Empreendível e Crucial; [B] Empreendível e Condicionante; [C] Empreendível e Pouco condicionante e [D] Irrelevante.

Adicionalmente, foram estabelecidos os quantitativos e faixas acerca da demanda operacional pertinente a cada uma dessas características, sendo classificadas em quatro grupos, de acordo com sua disponibilidade na área determinada: [W] Supera; [X] Atende; [Y] Insuficiente e [Z] Inexistente.

\subsection{Profundidade do Costado e Canal de ACesso (Calado)}

A profundidade do polígono relevante de costado e do canal de acesso da área em análise figura como um dos critérios a serem observados e levantados na escolha da área.

Segundo o Relatório Final do Plano Geral de Outorgas (PGO) da Agência Nacional de Transportes Aquaviários (ANTAQ), as embarcações utilizadas no comércio internacional, por razões de economia de escala no transporte marítimo, evoluíram significativamente em tamanho e calado, exigindo profundidades operacionais cada vez maiores.

Já os barcos utilizados na logística offshore são, por razões operacionais, de menor porte, geralmente PSV - Platform Supply Vessel -, com 80 metros de comprimento, 20 de largura e calado de $6 \mathrm{~m}$, demandando uma profundidade mínima operacional de 7 metros.

A estabilidade do canal de acesso quanto ao solo marinho no tocante à estabilidade da lamina d'água, identificando pontos de acumulação naturais ou ainda formações potenciais ou sazonais de bancos de areia, também devem ser levados em conta no estudo locacional.

Assim, a seguir o vetor respectivo a esta característica:

\begin{tabular}{|c|c|c|c|c|c|c|}
\hline \multirow{2}{*}{ Critério locacional } & \multirow{2}{*}{ Categoria } & \multirow{2}{*}{$\begin{array}{c}\text { Índice } \\
\text { Relevância }\end{array}$} & \multicolumn{3}{|c|}{ Grau de Relevância } \\
\cline { 5 - 7 } & & & X & Y & Z \\
\hline Profundidade do Costado e Canal de Acesso (calado) & Meio Ambiente & A & $>10 m$ & $10-7 m$ & $4-7 m$ & $<4 m$ \\
\hline
\end{tabular}

2.2 Áreas de Proteção Ambiental, Terras Indígenas, QUilombolas, Áreas Turísticas ou Áreas COM InCIDÊNCIA de Recifes; PossibILIDAde de Transbordo de

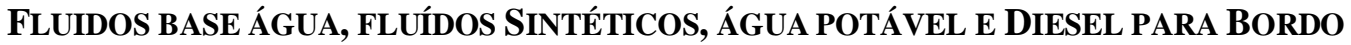

O licenciamento ambiental de um projeto de base de apoio logístico offshore junto ao órgão regulador ambiental - no caso brasileiro o IBAMA - é uma etapa de grande complexidade processual e legal, normalmente desempenhada por consultorias especializadas, cuja completa exposição fugiria ao escopo principal deste trabalho. Porém, em linhas gerais, para obtenção das licenças necessárias à consecução do projeto, o empreendedor deve apresentar ao órgão ambiental, dentre outros documentos, o Estudo de Impacto Ambiental EIA -, seu subsequente Relatório de Impacto Ambiental - RIMA - e seu Plano de Emergência Individual - PEI, no qual constam a descrição em detalhes dos serviços e metodologias adotadas na operação da base, bem como seus recursos, instrumentos e práticas para mitigação de eventuais acidentes.

Com base nestes documentos (dentre outros) e na área em referência, o regulador irá deferir ou indeferir a licença para construção e para certas operações, dentre as quais as classes de fluidos que poderão ser bombeados diretamente aos tanques dos navios, que são diversas, desde água potável a óleo diesel e fluidos de perfuração, sendo este serviço 
altamente característico de uma base de apoio logístico offshore. O ideal é que a área seja habilitada a transbordar todos os tipos de fluidos utilizados na indústria do petróleo, sendo os principais os fluidos base água, o óleo diesel e a água potável.

Na avaliação da área, o empreendedor deverá atentar para sua distância das áreas de proteção ambiental, de terras indígenas ou quilombolas. A ANTAQ preconiza em seu PGO uma distancia mínima de 10km dessas áreas para implementação e projetos portuários.

Já a incidência de recifes pode constituir um grande problema para o estabelecimento de um porto ou uma base de apoio offshore pois reduzem a lamina d'agua útil local. Dada a instabilidade marítima (ondas e marés), o risco de sinistro pela operação de embarcações nestas áreas será um custo adicional que o cliente do operador logístico irá computar em sua estrutura, comprometendo a competitividade de preços de um prestador de serviços portuários estabelecido neste local. Ademais, áreas com grande incidência de recifes em geral guardam grande fauna e flora marinha que, potencialmente, poderão dificultar o licenciamento do estabelecimento da base pelo órgãos competentes.

Áreas turísticas também devem ser evitadas no processo de avaliação. O turismo na costa brasileira se dá basicamente pela exploração dos ativos naturais das regiões (as belas praias, enseadas, etc.) sempre explorando a beleza, cultura e idiossincrasias naturais das localidades. Adicionalmente, o turismo costeiro guarda uma relação estreita, muitas vezes até exploratória, com a integridade e preservação da fauna e flora marinhas local, que podem vir a ser comprometidas pela indústria portuária. A atividade logística offshore não costuma guardar afinidade com a indústria turística, pelo contrário. Sítios portuários em geral possuem instalações que não primam pela beleza, sendo cercados de armazéns, hubs de distribuição, são grandes emissores de resíduos e poluição, com movimentação de barcos cargueiros de médio/grande porte, enfim, aspectos que geram externalidades negativas à indústria do turismo.

Além disso, o desenvolvimento urbanístico pré-existente numa localidade cujo turismo é bem desenvolvido poderá vir a ser extremamente inapropriado à própria dinâmica da atividade portuária que demanda vias adequadas para acesso e movimentação de veículos de grande porte, interligando o litoral às rodovias mais próximas, algo incomum no padrão de desenvolvimento de localidades tipicamente turísticas ao longo da costa brasileira.

Logo, sob uma ótica de cunho social, uma região cuja economia é bem estabelecida em torno do turismo, deve ser evitada como possível local de estabelecimento de uma base de apoio logístico.

Assim, a seguir os vetores respectivos a estas características:

\begin{tabular}{|c|c|c|c|c|c|c|}
\hline \multirow{2}{*}{ Critério locacional } & \multirow{2}{*}{ Categoria } & \multirow{2}{*}{$\begin{array}{c}\text { Índice } \\
\text { Relevância }\end{array}$} & \multicolumn{4}{|c|}{ Grau de Relevância } \\
\hline & & & $\mathbf{W}$ & $\mathbf{x}$ & $\mathbf{Y}$ & $\mathbf{Z}$ \\
\hline $\begin{array}{l}\text { Terras Indígenas, Quilombolas, Áreas } \\
\text { Turísticas, Recifes, Área de Proteção } \\
\text { Ambiental - APA }\end{array}$ & $\begin{array}{c}\text { Meio } \\
\text { Ambiente }\end{array}$ & A & $>15 \mathrm{~km}$ Raio & 15-10km Raio & 10-0km Raio & Okm Raio \\
\hline $\begin{array}{l}\text { Possibilidade de Transbordo de Fluidos } \\
\text { base água, fluídos Sintéticos, água } \\
\text { potável e Diesel para Bordo }\end{array}$ & Produção & B & Todos & $\begin{array}{l}\text { Fluídos base } \\
\text { água / água } \\
\text { pot / diesel }\end{array}$ & $\begin{array}{l}\text { Somente } \\
\text { água } \\
\text { potável }\end{array}$ & Nenhum \\
\hline
\end{tabular}

\subsection{LARgura do CANAl DE ACESSO}

A largura do canal de acesso é outro item importante a ser observado, principalmente em áreas tipo enseada. Porém, para atividade offshore este item é facilitado pelo pequeno porte dos navios, em geral PSVs com 20 metros de largura.

Assim, a seguir o vetor respectivo a esta característica: 


\begin{tabular}{|c|c|c|c|c|c|c|}
\hline \multirow{2}{*}{ Critério locacional } & \multirow{2}{*}{ Categoria } & \multirow{2}{*}{$\begin{array}{c}\text { Índice } \\
\text { Relevância }\end{array}$} & \multicolumn{4}{|c|}{ Grau de Relevância } \\
\hline & & & $\mathbf{W}$ & $\mathbf{x}$ & $\mathbf{Y}$ & $\mathbf{Z}$ \\
\hline Largura do Canal de Acesso & $\begin{array}{c}\text { Meio } \\
\text { Ambiente }\end{array}$ & B & $>100 \mathrm{~m}$ & $100-30 \mathrm{~m}$ & $30-10 m$ & $<10 \mathrm{~m}$ \\
\hline
\end{tabular}

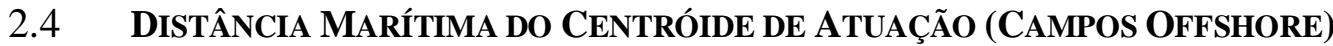

Temos aqui um aspecto natural e o principal fator locacional para estabelecimento de uma base de apoio logístico offshore. Definidas as áreas possíveis, o dado mais importante a se verificar no momento da escolha do local da base que fará o apoio logístico onshore de uma operação offshore é sua distância dos campos aos quais servirá. Uma boa escolha refletirá nos custos da operação em várias frentes, direta e indiretamente.

Natural e diretamente, quanto maior o tempo de traslado entre a base em terra e a instalação offshore mais oneroso tenderá a ser esse transporte. Porém, este não é o único ônus e a justificativa de custos a favor de uma opção mais próxima não é de trivial mensuração nem tão imediata. Quanto mais próxima for a instalação de apoio onshore de seu campo, mais ágeis tendem a ser as respostas das operações em terra frente às necessidades que surgem nas operações offshore, desde as rotineiras às imprevistas, pessoais ou materiais.

A atividade de exploração e produção de petróleo offshore é altamente intensiva em capital. Erros, desvios ou ineficiências operacionais de qualquer natureza terão significativo impacto na estrutura de custos, agravados pelo caráter remoto das instalações. Os custos de locação dos equipamentos utilizados na produção de petróleo não são nada desprezíveis, contabilizados em unidades mínimas de tempo, e só se justificam sob uma utilização otimizada e corretamente concatenada com os processos de produção e demais recursos interdependentes. Por exemplo, uma pane em um equipamento chave pode custar a interrupção das operações de toda uma instalação de produção. Caso o reestabelecimento de seu funcionamento demande alguma ação cujo provimento se dá em terra, seja no embarque de um novo componente, seja no envio de pessoal especializado para realizar o reparo, esta distância se revela crucial para a estrutura de custos da operação e sua viabilidade técnica e econômica. Ou seja, no fluxo de caixa de um projeto de 20, 25 anos, um quilômetro pode significar milhões.

Naturalmente, isso se traduz em uma vantagem competitiva aos espaços e instalações em terra mais próximas dos campos, cujos serviços serão precificados levando-se em conta todas essas idiossincrasias particulares da indústria do petróleo: quanto mais perto for minha instalação de seu campo, mas caro será meu serviço. Para reforçar o forte sentido econômico dessa conduta de mercado, o diferencial positivo nos preços que um operador logístico bem posicionado poderá vir a cobrar representará um custo deterministico à companhia petrolífera, sem incerteza, definido em um contrato de prestação de serviços para um prazo bem delimitado para ambas as partes. O contrário ocorre para este custo adicional por quilômetro, que elevará eventuais prejuízos por paradas operacionais e que devem ser levantados de forma estocástica, com múltiplas variáveis de análise, em longos horizontes de tempo, permeados pelas mais diversas formas de risco e incerteza, sejam físicas, legais, políticas e operacionais, cada uma delas elevando o custo de levantamento e projeção dos custos operacionais e além, reduzindo o grau de aderência entre o orçado e o realizado, o que se traduz em uma maior taxa de retorno exigida para viabilização e execução do empreendimento exploratório.

Em termos de mercado, é desejável que distancia reflita um tempo de navegação baseinstalaçao offshore dentro de um intervalo de 12 a 24 horas.

Assim, a seguir o vetor respectivo a esta característica:

\begin{tabular}{|l|l|l|l|}
\hline Critério locacional & Categoria & Índice & Grau de Relevância \\
\hline
\end{tabular}




\begin{tabular}{|l|c|c|c|c|c|c|}
\hline & & Relevância & W & X & Y \\
\hline $\begin{array}{l}\text { Distancia Marítima do } \\
\begin{array}{l}\text { Centroide de Atuação (Campos } \\
\text { Offshore) }\end{array}\end{array}$ & Produção & A & $\begin{array}{c}\text { Tempo } \\
\text { navegação } \\
<12 h\end{array}$ & $\begin{array}{c}\text { Tempo } \\
\text { navegação 12- } \\
24 h\end{array}$ & $\begin{array}{c}\text { Tempo } \\
\text { navegação } \\
24-36 h\end{array}$ & $\begin{array}{c}\text { Tempo } \\
\text { navegação } \\
>36 h\end{array}$ \\
\hline
\end{tabular}

\subsection{EXISTÊNCIA E DISPONIBILIDADE DE BERÇOS DE ATRACAÇÃo}

Temos aqui outro fator de extrema importância na escolha de uma área para implementação de um terminal de apoio logístico offshore. A existência e disponibilidade de espaço útil para construção de berços para atracação, tanto no costado como projetados offshore, definirá o volume operacional potencial da área. Além de possibilitar maiores receitas em virtude do maior número de operações de transbordo simultâneas, uma base de apoio logístico goza de economias de escala em muitos dos seus processos, o que se traduz em eficiência e menor custo por operação.

Grande volume operacional também significa oportunidades para novos negócios que dependem de escala para viabilização. Um bom exemplo de negócio com essa característica seria a dotação por parte do operador logístico de frota própria (que pode ser tanto comprada como alugada) de containers de uso repetido, específicos ao serviço da indústria offshore, para aluguel spot aos clientes. Como não figura como seu principal negócio, uma base de apoio logístico não terá bons preços de locação se comparados a fornecedores específicos desse tipo de equipamento. Porém, as demandas inesperadas dos clientes por este tipo de equipamento são frequentes e sua criticidade operacional é alta, o que gera uma boa oportunidade de negócio ao operador logístico que, por locações spot, pode vir a cobrar ágios relevantes sobre os preços de mercado desses equipamentos, porém ainda razoáveis frente aos potenciais prejuízos caso o transporte não seja realizado. E para o cliente, a disponibilidade desse serviço se traduz em segurança operacional, elevando a percepção do valor e seu excedente do consumidor.

Adicionalmente, uma base de grande volume operacional tenderá a ser mais atrativa à fixação de capitais industriais produtivos fornecedores da indústria do petróleo em seu entorno, elevando a agilidade operacional e contribuindo para o aumento do valor percebido e o excedente do consumidor do operador do campo quanto ao serviço desenvolvido nesta base

Assim, a seguir o vetor respectivo a esta característica:

\begin{tabular}{|c|c|c|c|c|c|c|}
\hline \multirow{2}{*}{ Critérios locacionais } & \multirow{2}{*}{ Categoria } & \multirow{2}{*}{$\begin{array}{c}\text { Índice } \\
\text { Relevância }\end{array}$} & \multicolumn{4}{|c|}{ Grau de Relevância } \\
\hline & & & $\mathbf{w}$ & $x$ & $Y$ & Z \\
\hline $\begin{array}{l}\text { Existência e Disponibilidade } \\
\text { de Berço }\end{array}$ & Engenharia & B & $\begin{array}{c}1 \text { Berço } \\
\text { Disponível } \\
\text { (>100m) }\end{array}$ & $\begin{array}{c}\text { 1 Berço } \\
\text { Disponível } \\
(=100 \mathrm{~m})\end{array}$ & $\begin{array}{c}1 \text { Berço } \\
\text { Disponível } \\
(<100 \mathrm{~m})\end{array}$ & $\begin{array}{l}\text { Nenhum Berço } \\
\text { Disponível }\end{array}$ \\
\hline
\end{tabular}

\subsection{Proximidade de grandes Centros e capitais; Proximidade de insumos; Mão de OBRA E FORÇA DE TRABALHO LOCAL}

Em raciocínio análogo ao distanciamento base-campo de petróleo, a distância entre o empreendimento e um grande centro, fornecedores de insumos e mão de obra, impactarão tanto no capex como no opex do projeto e devem ser levados em conta no estudo locacional.

Naturalmente, áreas localizadas em zonas relativamente desenvolvidas em termos de estrutura e recursos serão mais caras que terrenos mais remotos. Em contrapartida, em uma área remota todos os demais custos serão mais elevados em virtude da dificuldade logística. Tudo haverá de ser "importado", os fretes serão mais caros em virtude das maiores distâncias percorridas, elevar-se-ão os riscos e os custos operacionais em razão da perda de agilidade e elevação do tempo de resposta frente à imprevistos que demandem recursos dos grandes centros, etc., além da elevação dos custos da mão de obra. Atrair bons recursos humanos para 
áreas remotas de operação demanda a prática de salários acima do valor de mercado. Cabe salientar que um operador logístico não é uma empresa de petróleo, é essencialmente um prestador de serviço, sendo sua estrutura muito intensiva em mão de obra.

A implementação de uma base que dista, supondo, mais de $100 \mathrm{~km}$ de um grande centro gerador da mão de obra especializada demandada, deverá sofrer de provisionamento extra em seu capex e principalmente em seu opex dados os custos elevados que o empreendimento terá com mão de obra, pelo menos no curto e médio prazo.

Outra ótica deste raciocínio vale para os formuladores de política de desenvolvimento e arranjos produtivos locais. Caso a mão de obra demandada pelo arranjo não seja produzida localmente, a renda gerada nesta região sofrerá uma evasão. Os trabalhadores virão de outras regiões e, principalmente aqueles mais especializados, geradores das grandes rendas, não assentarão no local residência permanente, transferindo suas rendas para seus locais de origem. Porém, a grande maioria das funções em uma base de apoio logístico é de nível técnico, possibilitando formação rápida e a baixo custo da força de trabalho local em programa que pode vir a ser promovido e fomentado pelo formador de politica do APL.

Assim, a seguir os vetores respectivos a estas características:

\begin{tabular}{|c|c|c|c|c|c|c|}
\hline \multirow{2}{*}{ Critérios locacionais } & \multirow{2}{*}{ Categoria } & \multirow{2}{*}{$\begin{array}{c}\text { Índice } \\
\text { Relevância }\end{array}$} & \multicolumn{4}{|c|}{ Grau de Relevância } \\
\hline & & & $\mathbf{w}$ & $\mathbf{x}$ & $\mathbf{Y}$ & $\mathbf{Z}$ \\
\hline $\begin{array}{l}\text { Proximidade de Insumos } \\
\text { (Fornecedores Diversos, } \\
\text { Transportadores e Empresas de } \\
\text { Destinação de Resíduos) }\end{array}$ & Produção & B & Raio $<50 \mathrm{~km}$ & $\begin{array}{l}\text { Raio 50- } \\
\text { 100km }\end{array}$ & $\begin{array}{c}\text { Raio } 100- \\
500 \mathrm{~km}\end{array}$ & Raio $>500 \mathrm{~km}$ \\
\hline $\begin{array}{l}\text { Proximidade de Grandes } \\
\text { Centros/Capitais }\end{array}$ & Produção & B & Raio $<50 \mathrm{~km}$ & $\begin{array}{l}\text { Raio } 50- \\
100 \mathrm{~km}\end{array}$ & $\begin{array}{l}\text { Raio } 100- \\
500 \mathrm{~km}\end{array}$ & Raio $>500 \mathrm{~km}$ \\
\hline Força de Trabalho Local & Produção & C & Okm & $1-5 \mathrm{~km}$ & $5-10 \mathrm{~km}$ & $>10 \mathrm{~km}$ \\
\hline
\end{tabular}

\subsection{PROXIMIDAde de ÁREAS RESIDENCIAIS - ZONEAMENTO}

A despeito do problema com licenciamento, a proximidade de áreas residenciais, quando não for um impeditivo para a seleção de uma área, pode revelar-se um ônus a médio/longo prazo, no decorrer da operação. Por exemplo, uma base de apoio demanda infraestrutura específica quanto aos seus acessos via terra para permitir movimentação de carretas de grande porte. Se a comunicação da área costeira portuária com a rodovia se der por vias estreitas, perpassando áreas densamente populadas, é grande a probabilidade de ocorrência de problemas operacionais, tanto por impedimento de embarque de certos equipamentos quanto por atrasos nos tempos de transporte. Aqui, a infraestrutura preexistente, por sua inadequação à atividade, é um revés para a alternativa locacional em questão.

Adicionalmente, em locais residenciais maiores tendem a ser os preços das áreas e espaços terrestres, elevando os custos do empreendimento. Porém, isso refletirá tanto no custo de estabelecimento da base quanto no preço de serviço que o operador logístico poderá vir a praticar aos seus clientes: trivialmente, a instalação de fornecedores típicos da indústria do petróleo em locais próximos à base de apoio será um diferencial competitivo. Tais fornecedores geralmente demandam grandes áreas para armazenamento de materiais, terminais de containers, etc. Alinhado com a ótica e propósito dos arranjos produtivos locais, ter uma gama de fornecedores alocados próximos à base sugere desoneração dos custos operacionais das empresas de petróleo que por ali operam - agilidade operacional, queda no valor de custos de transporte e fretes, etc. -, agregando valor ao serviço praticado naquela base em específico, refletindo-se no preço cobrado pelo serviço da operação logística naquele local. E, sendo baixos os preços das áreas vizinhas ou próximas à base, o fornecedor fica muito mais estimulado a ali se estabelecer, ocorrendo uma espécie de troca de externalidades 
positivas catalisadoras do APL, onde todos ganham, tornando o sistema como um todo muito mais eficiente: o operador (logístico) pratica um preço maior, justificado dentro do excedente do consumidor do cliente (empresa de petróleo) que por sua vez gozará pela desoneração em seus custos de transportes e fretes e pelo ganho de agilidade operacional (dinâmica com fornecedores).

Assim, a seguir o vetor respectivo a esta característica:

\begin{tabular}{|c|c|c|c|c|c|c|}
\hline \multirow{2}{*}{ Critérios locacionais } & \multirow{2}{*}{ Categoria } & \multirow{2}{*}{$\begin{array}{c}\text { Índice } \\
\text { Relevância }\end{array}$} & \multicolumn{4}{|c|}{ Grau de Relevância } \\
\hline & & & $\mathbf{w}$ & $\mathbf{x}$ & $\mathbf{Y}$ & Z \\
\hline $\begin{array}{l}\text { Proximidades de Áreas } \\
\text { Residenciais - Zoneamento }\end{array}$ & Meio Ambiente & B & $>5 \mathrm{~km}$ Raio & $\begin{array}{c}\text { 1-5km } \\
\text { Raio }\end{array}$ & 0-1km Raio & Okm Raio \\
\hline
\end{tabular}

\subsection{REDE DE ESGOTO, REDE DE ÁGUA, ENERGIA ELÉTRICA E TELECOMUNICAÇÕES}

Naturalmente, como qualquer instalação industrial, uma base de apoio logístico offshore demanda energia elétrica e comunicação com as redes de água, esgoto e telecomunicações. Quanto maior a distancia dessas redes, maiores serão os custos de implantação da base de apoio e menos atraente será a área em questão.

Assim, a seguir os vetores respectivos a estas características:

\begin{tabular}{|c|c|c|c|c|c|c|}
\hline \multirow{2}{*}{ Critérios locacionais } & \multirow{2}{*}{ Categoria } & \multirow{2}{*}{$\begin{array}{c}\text { Índice } \\
\text { Relevância }\end{array}$} & \multicolumn{4}{|c|}{ Grau de Relevância } \\
\hline & & & $\mathbf{w}$ & $x$ & $\mathbf{Y}$ & $\mathbf{Z}$ \\
\hline Telecomunicações & Engenharia & B & $\begin{array}{l}\text { Rede Fixa + } \\
\text { Rede Móvel }\end{array}$ & Rede Fixa & Rede Móvel & Nenhum \\
\hline Rede de Esgoto & Engenharia & $\mathrm{C}$ & 0km & $1-5 \mathrm{~km}$ & $5-10 \mathrm{~km}$ & $>10 \mathrm{~km}$ \\
\hline Energia Elétrica & Produção & $B$ & 0km & $1-5 \mathrm{~km}$ & $5-10 \mathrm{~km}$ & $>10 \mathrm{~km}$ \\
\hline Rede de Água (Vazão) & Produção & $B$ & $>30 \mathrm{~m}^{3} / \mathrm{h}$ & $20-30 \mathrm{~m}^{3} / \mathrm{h}$ & $5-20 m^{3} / h$ & $<5 m^{3} / h$ \\
\hline
\end{tabular}

\subsection{PROXIMIDADE DE RODOVIAS, AEROPORTOS/HELIPORTOS E FERROVIAS}

Como uma base de apoio logístico offshore é um elo multimodal, imprescindível sua proximidade e ligação aos modais terrestres, principalmente o rodoviário, no qual são transportadas a maioria das cargas pertinentes à indústria de petróleo. Condição adequada em seu acesso por terra é um grande condicionante do bom fluxo operacional da base de apoio logístico offshore.

Adicionalmente, dada a criticidade do fator tempo na indústria do petróleo, áreas com boa ligação e proximidade a rodovias de porte gozarão de significativas vantagens competitivas por mitigarem riscos operacionais. Assim, à proximidade de rodovias é atribuído um índice de relevância maior frente aos modais ferroviário e aeroviário na nossa proposta.

Assim, a seguir os vetores respectivos a estas características

\begin{tabular}{|c|c|c|c|c|c|c|}
\hline \multirow{2}{*}{ Critérios locacionais } & \multirow{2}{*}{ Categoria } & \multirow{2}{*}{$\begin{array}{c}\text { Índice } \\
\text { Relevância }\end{array}$} & \multicolumn{4}{|c|}{ Grau de Relevância } \\
\hline & & & $\mathbf{W}$ & $\mathrm{X}$ & $\mathbf{Y}$ & $\mathbf{Z}$ \\
\hline Proximidade de Rodovias & Transporte & $\mathrm{B}$ & $<10 \mathrm{~km}$ & $10-50 \mathrm{~km}$ & $10-100 \mathrm{~km}$ & $>50 \mathrm{~km}$ \\
\hline $\begin{array}{l}\text { Proximidade de } \\
\text { Aeroportos/Heliportos }\end{array}$ & Transporte & C & $0 \mathrm{~km}$ & $1-5 \mathrm{~km}$ & $5-10 \mathrm{~km}$ & $>10 \mathrm{~km}$ \\
\hline Proximidade de Ferrovias & Transporte & C & Okm & $1-5 \mathrm{~km}$ & $5-10 \mathrm{~km}$ & $>10 \mathrm{~km}$ \\
\hline
\end{tabular}

\subsection{TOPOGRAFIA, DECLIVIDAdE E RESISTÊNCIA DE SOLO; TIPO DE SOLO}


Como circularão e serão armazenados maquinário e materiais pesados, as condições e o tipo do solo são fundamentais para a operação de uma base de apoio logístico. O solo deve ser estável, resistente e bem compactado. O padrão de exigência do mercado para resistência de solo é de cinco toneladas por metro quadrado.

O mesmo vale para seu nivelamento. Como muitos materiais são armazenados empilhados (por ex. containers e tanques) um solo desnivelado compromete a capacidade de empilhamento, fazendo com que um mesmo quantitativo de material demande mais área locada pelo cliente para armazenamento, reduzindo o valor agregado do serviço da base.

A necessidade de terraplanagem e aterramento eleva os custos do empreendimento e reduz o grau de atratividade da área em questão.

Assim, a seguir os vetores respectivos a estas características

\begin{tabular}{|c|c|c|c|c|c|c|}
\hline \multirow{2}{*}{ Critérios locacionais } & \multirow{2}{*}{ Categoria } & \multirow{2}{*}{$\begin{array}{c}\text { Índice } \\
\text { Relevância }\end{array}$} & \multicolumn{4}{|c|}{ Grau de Relevância } \\
\hline & & & $w$ & $x$ & $Y$ & $z$ \\
\hline $\begin{array}{l}\text { Topografia, Declividade e } \\
\text { Resistencia de Solo }\end{array}$ & Engenharia & B & $\begin{array}{l}\text { Nivelado e } \\
>5 \text { ton } / \mathrm{m}^{2}\end{array}$ & $\begin{array}{l}\text { Nivelado e } \\
=5 \text { ton } / \mathrm{m}^{2}\end{array}$ & $\begin{array}{l}\text { Desnivelado } \\
\text { ou }<5 \text { ton } / \mathrm{m}^{2}\end{array}$ & $\begin{array}{l}\text { Desnivelado } \\
\mathrm{e}<5 \text { ton } / \mathrm{m}^{2}\end{array}$ \\
\hline Tipo de Solo & $\begin{array}{c}\text { Meio } \\
\text { Ambiente }\end{array}$ & A & $\begin{array}{l}\text { Aterro 1a } \\
\text { Categoria } \\
\text { com Areia }\end{array}$ & $\begin{array}{c}\text { Aterro 2a } \\
\text { Categoria } \\
\text { com Bica } \\
\text { Corrida }\end{array}$ & Pedra & $\begin{array}{c}\text { Charco } \\
\text { (mangue) ou } \\
\text { argila mole }\end{array}$ \\
\hline
\end{tabular}

\subsection{ABRIGO A ONDAS, CORRENTES E INTEMPÉRIES MARÍTIMAS}

A operação de transbordo de cargas requer uma mínima estabilidade da embarcação principalmente por razões de segurança operacional. Logo, áreas adequadas ao estabelecimentos de terminais de atracação devem ser abrigadas de ondas e correntes. Naturalmente, barreiras com este fim são empreendíveis, contudo, geralmente, sob alto custo, reduzindo a competitividade dessas áreas frente a outras.

Assim, a seguir o vetor respectivo a esta característica

\begin{tabular}{|c|c|c|c|c|c|c|}
\hline \multirow{2}{*}{ Critérios locacionais } & \multirow{2}{*}{ Categoria } & \multirow{2}{*}{$\begin{array}{c}\text { Índice } \\
\text { Relevância }\end{array}$} & \multicolumn{4}{|c|}{ Grau de Relevância } \\
\hline & & & $\mathbf{W}$ & $x$ & $Y$ & $\mathbf{Z}$ \\
\hline $\begin{array}{l}\text { Abrigo a ondas, correntes e } \\
\text { intempéries marítimas }\end{array}$ & $\begin{array}{c}\text { Meio } \\
\text { Ambiente }\end{array}$ & B & $\begin{array}{l}\text { Abrigo } \\
\text { natural }\end{array}$ & $\begin{array}{c}\text { Abrigo } \\
\text { empreendido }\end{array}$ & $\begin{array}{l}\text { Abrigo não } \\
\text { empreendido }\end{array}$ & $\begin{array}{c}\text { Não } \\
\text { abrigável }\end{array}$ \\
\hline
\end{tabular}

\subsection{CONDIÇÕES DE VENTO PREDOMINANTES}

A operação de transbordo nas bases de apoio logístico offshore se assemelha às plataforma e navios de petróleo, sendo as cargas e containers içados por guindastes através de eslingas (operação já detalhada anteriormente). Neste tipo de içamento, a ação dos ventos adquire sobre importância, sendo fator vital na segurança da operação.

Locais com predominância de ventos fortes devem ser preteridos em relação aos locais mais calmos. A tabela abaixo, extraída do website do INPE, exibe a escala Beaufort de força de ventos, na qual está baseada nosso vetor de relevância. 


\begin{tabular}{|c|c|c|c|c|c|c|}
\hline \multicolumn{7}{|c|}{ Escala Beaufort de Força de Vento } \\
\hline \multirow{2}{*}{ Escala } & \multicolumn{2}{|c|}{ Velocidade média } & \multicolumn{2}{|c|}{ Velocidades limites } & \multicolumn{2}{|c|}{ Nomenclatura } \\
\hline & $\mathrm{ms}^{-1}$ & nós \{knots\} & $\mathrm{ms}^{-1}$ & nós \{knots\} & português & inglềs \\
\hline 0 & 0 & 0 & $\leqslant 1$ & $<1$ & Calmaria & Calm \\
\hline 1 & 1 & 2 & $1-2$ & $1-3$ & Eafagem & Light ث..ir \\
\hline 2 & 3 & $E$ & $2-4$ & $4-5$ & Aragem & Light Breeze \\
\hline 3 & 5 & 9 & $4-5$ & $7-10$ & Fraco & Gentle Brezze \\
\hline 4 & 7 & 13 & $5-9$ & $11-15$ & 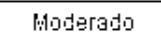 & Moderate Ereeze \\
\hline 5 & 10 & 19 & $9-11$ & $17-21$ & Fresco & Fresh Breeze \\
\hline 6 & 12 & 24 & $11-14$ & $22-27$ & Muito Fresco & Strong Ereeze \\
\hline 7 & 15 & 30 & $14-17$ & $28-33$ & Forte & Near Gale \\
\hline 8 & 19 & 37 & $17-21$ & $34-40$ & Muito Forte & Gale \\
\hline 9 & 23 & 44 & $21-25$ & $41-47$ & Duro & Severe Gale \\
\hline 10 & 27 & 52 & $25-29$ & $48-55$ & Piluito Duro & Storm \\
\hline 11 & 31 & 50 & $29-33$ & $55-63$ & Tempestuoso & Violent Storm \\
\hline 12 & - & - & $33+$ & $54+$ & Furacẫ & Hurricane \\
\hline
\end{tabular}

Fonte: INPE - CPTEC

Assim, a seguir o vetor respectivo a esta característica.

\begin{tabular}{|l|c|c|c|c|c|c|}
\hline \multirow{2}{*}{ Critérios locacionais } & Categoria & índice & \multicolumn{4}{|c|}{ Grau de Relevância } \\
\cline { 4 - 6 } & & Relevância & W & X & Y & Z \\
\hline $\begin{array}{l}\text { Condições de Vento } \\
\text { Predominantes }\end{array}$ & Meio Ambiente & B & 0-2 Beaufort & 3-5 Beaufort & 6-9 Beaufort & $\begin{array}{c}10-12 \\
\text { Beaufort }\end{array}$ \\
\hline
\end{tabular}

\subsection{DISPONIBILIDADE DE RETROÁREA PARA ARMAZENAMENTO DE MATERIAIS E PARADA DE CARRETAS}

A disponibilidade de retroárea para armazenagem de materiais e parada de carretas é um item de grande importância a ser observado no processo de seleção da área para implementação do projeto. Ainda que o operador possa fornecer serviço de armazenagem por longa duração de materiais, o qual frequentemente será ofertado e alocado em áreas externas à área portuária, uma área subjacente ao porto se faz necessária para armazenagem dos materiais em trânsito e parada de carretas, evitando que estas aguardem serviço nas vias públicas e eventuais transtornos no trânsito local.

Assim, a seguir o vetor respectivo a esta característica

\begin{tabular}{|c|c|c|c|c|c|c|}
\hline \multirow{2}{*}{ Critérios locacionais } & \multirow{2}{*}{ Categoria } & \multirow{2}{*}{$\begin{array}{c}\text { Índice } \\
\text { Relevância }\end{array}$} & \multicolumn{4}{|c|}{ Grau de Relevância } \\
\hline & & & $\mathbf{w}$ & $\mathrm{x}$ & $\mathbf{Y}$ & $\mathbf{Z}$ \\
\hline $\begin{array}{l}\text { Disponibilidade de } \\
\text { Retroárea para } \\
\text { Armazenamento de } \\
\text { Materiais }\end{array}$ & Produção & B & $>5 \mathrm{~km}$ Raio & 1-5km Raio & 0-1 km Raio & Okm Raio \\
\hline
\end{tabular}

\subsection{MATRIZ FINAL DE CRITÉRIOS LOCACIONAIS}

Dispostos os critérios, temos então proposta a matriz final de características e aspectos locacionais relevantes na escolha de uma região e área para implementação e construção de bases de apoio logístico offshore.

Matriz Final de Critérios Locacionais

\begin{tabular}{|c|l|c|c|c|c|c|c|}
\hline$\#$ & \multicolumn{1}{|c|}{ Critérios locacionais } & Categoria & $\begin{array}{c}\text { Índice } \\
\text { Relevância }\end{array}$ & W & X & Y \\
\hline 1 & $\begin{array}{l}\text { Profundidade do Costado e } \\
\text { Canal de Acesso (calado) }\end{array}$ & $\begin{array}{c}\text { Meio } \\
\text { Ambiente }\end{array}$ & A & $>10 \mathrm{~m}$ & $\mathbf{1 0 - 7 m}$ & $4-7 \mathrm{~m}$ & $<4 \mathrm{~m}$ \\
\hline
\end{tabular}




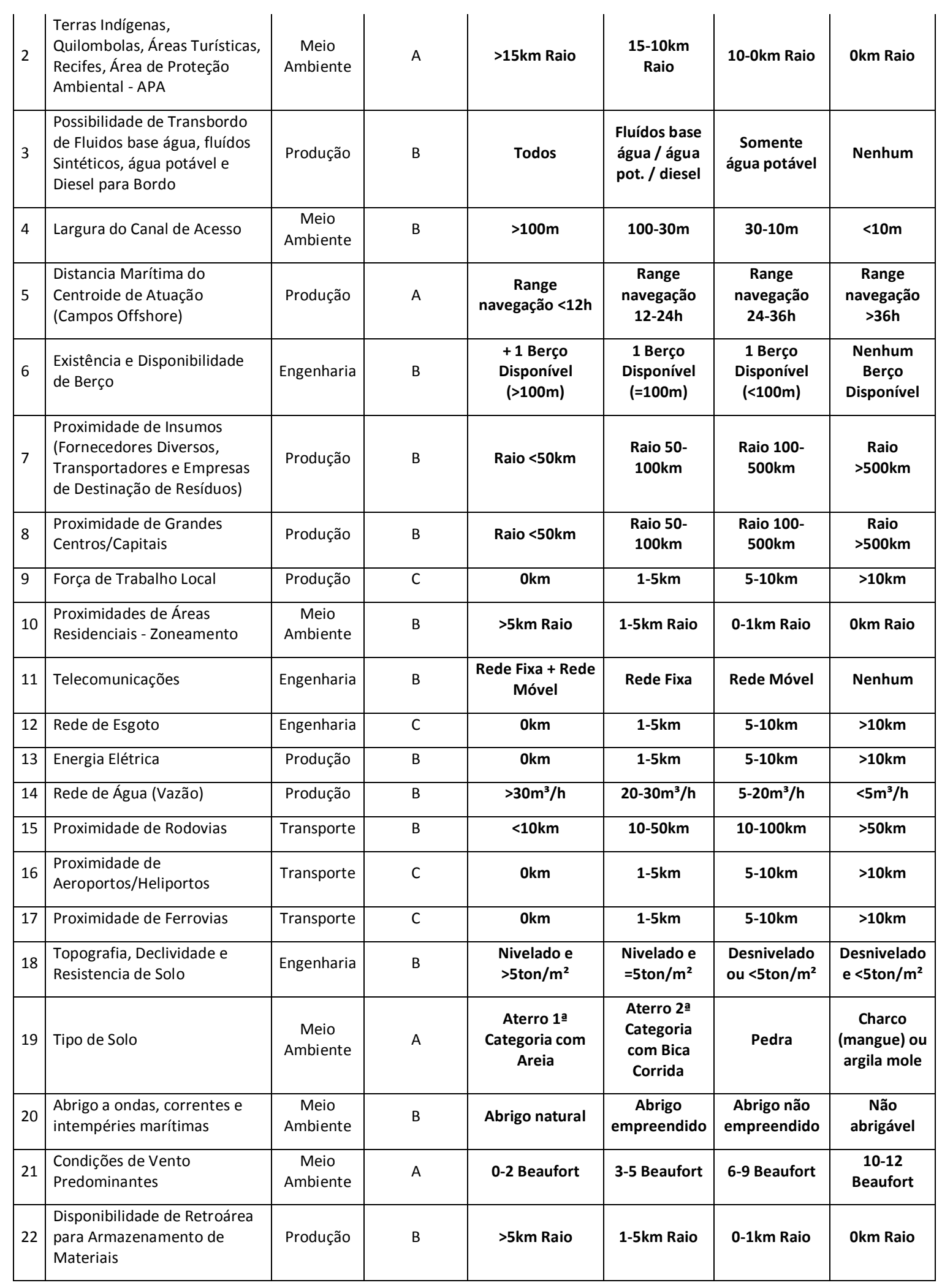

\section{REFERÊNCIAS BIBLIOGRÁFICAS}

[1] BRASIL. AGÊNCIA NACIONAL DE TRANSPORTES AQUAVIÁRIOS - ANTAQ. Manual de Licenciamento Ambiental de Portos. Disponível em $<$ http://www.antaq.gov.br/Portal/pdf/Meio_Ambiente/manual_de_licenciamento_ambie ntal_nos_portos_(2).pdf $\rangle$ 
[2] BRASIL. AGÊNCIA NACIONAL DE TRANSPORTES AQUAVIÁRIOS - ANTAQ. Subsídios Técnicos para Identificação de Áreas Destinadas à Instalação de Portos Organizados ou Autorização de Terminais de Uso Privativo em Apoio ao Plano Geral de Outorgas. Relatório Final, Tomo 1. 2009.

[3] BRASIL. INSTITUTO DE PESQUISA ECONÔMICA E APLICADA - IPEA. Portos Brasileiros: Diagnóstico, Políticas e Perspectivas. Comunicados do IPEA No 48. Brasília, 2010.

[4] BRASIL. MINISTÉRIO DA CIÊNCIA, TECNOLOGIA E INOVAÇÃO. INSTITUTO NACIONAL DE PESQUISAS ESPACIAIS. CENTRO DE PREVISÃO DE TEMPO E ESTUDOS CLIMÁTICOS. Website, notícias: Ciclone extratropical provoca ventos intensos no Sul. Disponível em <http://www.cptec.inpe.br/noticias/noticia/22557>.

[5] COSENZA, C. A. N. TOLEDO. O. M. Um caso de aplicação da Lógica Fuzzy - o Modelo Coppe-Cosenza de Hierarquia Fuzzy. XXIII Encontro Nacional de Engenharia de Produção. Ouro Preto, MG. 2003

[6] KUPFER, D. et al. Impacto Econômico da Expansão da Indústria do Petróleo Relatório Final. Organização Nacional da Indústria do Petróleo - ONIP, 2000.

[7] PINTO JR. et al. Economia da Energia - Fundamentos Econômicos, Evolução Histórica e Organização Industrial. Elsevier. São Paulo, 2007.

[8] SAMUELSON, P. Foundations of Economic Analysis. Harvard University Press. Cambridge, Massachusetts, USA. 1983.

[9] THOMAS, J. (org.). Fundamentos de Engenharia de Petróleo. 2a Ed. Interciência. Rio de Janeiro, 2004. 